 \\ A Corpus-Based Research on Ditransitive Constructions with Tell and Say
}

\section{Hafissatou KANE}

Department of English studies, Cheikh Anta DIOP University of Dakar, Senegal

Email: kanehafi@gmail.com

\section{Article History}

Received: January 10, 2021

Revised: February 22, 2021

Accepted: February 25, 2021

Published: February 27, 2021

\begin{abstract}
Learners' errors give insights to teachers, textbook writers, curriculum designers and many applied linguists about the learning difficulty in the acquisition of a target language. Studying systematically these errors is therefore considered indispensable in learning teaching process. Basing on the corpus-based model, this paper investigates the constructions of two ditransitive verbs: TELL and $S A Y$ which cause much trouble to second language learners. After analysing the exam copies of 200 second-year students in the English department of Cheikh Anta DIOP University of Dakar, the study comes up with two general observations. First, the analysis of the overall data shows that learners of the corpus largely prefer using TELL $(62,5 \%)$ to SAY $(14,5 \%)$. The second observation is, these students use more correctly the ditransitive form involving TELL than SAY. For instance, 79, $2 \%$ of them employ TELL in the double object construction corresponding to the basic structure TELL + someone + something, while only 5,1\% correctly use the dative construction of SAY which is SAY + something + to + someone. These findings conform to several studies which claim that the dative form is the most complicated construction, and is consequently the rarely used one. All of this indicates, that even if these students are English majors, they are still in their basic level in the acquisition of ditransitive constructions. This suggests that special strategies and mechanisms are required in teaching and learning ditransitive verbs. More efforts are also needed in teaching and learning constructions in grammar (e.g. alternating pairs like Passive /Active, Will /Be going to, Verb-particle constructions etc.). This will help students become more accurate in using English, the target language.

Keywords: Corpus-based research; Grammar; Ditransitive verb; TELL; SAY.
\end{abstract}

\section{Introduction}

In Richard and Schmidt (2002), a verb which takes an object, either direct or indirect, is called a transitive verb (e.g. "They saw the accident"), a verb which does not take an object is an intransitive verb (e.g. "The children danced") while a ditransitive verb is a verb which accepts an indirect and a direct object (e.g. "I gave the money to my mother" or "I gave my mother the money").

According to Goldberg (2003), constructions are stored pairings of form and function, including morphemes, words, and idioms, partially lexically filled and fully general linguistic patterns. For her, constructionist approaches share certain foundational ideas with the mainstream generative approach. Both approaches agree that it is essential to consider language as a cognitive (mental) system; both approaches acknowledge that there must be a way to combine structures to create novel utterances, and both approaches recognize that a non-trivial theory of language learning is needed.

Haspelmath (2005b) defines a ditransitive construction as a construction with a verb denoting transfer of an entity (T) from an agent (A) to a recipient (R), such as Kim gave Lee a box. This transfer, according to him, is most often possessive transfer (concrete as in 'give', 'lend', 'hand over', 'bequeath', or more abstract as in 'offer' and 'promise'), but cognitive transfer verbs ('show', 'teach') typically behave in much the same way and are therefore normally included in the ditransitive domain.

In English, two related constructions have been widely discussed, namely the double object construction (DOC), and the prepositional or dative construction (DAT). Alternating ditransitives refer to those verbs that can occur in both DOC and DAT (Xu, 2014).

According to construction Grammar (Goldberg, 2006), the configurations of the two constructions are as follows:

$\begin{array}{lllll}\text { DOC: } & \begin{array}{l}\text { Subj } \\ \text { Agent }\end{array} & \mathrm{V} & \begin{array}{c}\text { Obj1 } \\ \text { recipient }\end{array} & \begin{array}{l}\text { Obj2 } \\ \text { theme }\end{array} \\ & \text { John } & \text { gave } & \text { Mary } & \text { a book } \\ \text { DAT: } & \text { Subj } & \text { V } & \text { Obj } & \text { PP } \\ & \text { Agent } & & \text { theme } & \text { goal } \\ & \text { John } & \text { gave } & \text { a book } & \text { to Mary }\end{array}$


The literature reveals that there is quite some confusion with respect to the forms of encoding the theme (direct object) and recipient (indirect object) in several languages. Malchukov (2007) recognize that all languages have far fewer ditransitive verbs than transitive verbs, and the ditransitive verbs of a language do not necessarily behave uniformly.

The present study analyses the structure of ditransitive constructions of two English verbs: TELL and SAY which behave differently and cause much challenge to francophone learners.

The basic structure of TELL is: TELL someone something

The basic structure of $S A Y$ is: $S A Y$ something to someone

On the basis of a corpus data from students in the English department of Cheikh Anta DIOP university of Dakar (Senegal), the paper examines whether the structure of each construction is correctly used. In that effect, I first investigate the different complementation patterns of TELL and SAY in this learners' corpus. One particular focus of this section consists of identifying which between the double object and dative constructions is better mastered. A second objective is to identify what influences the acquisition of such form if there is any, in order to propose some pedagogical insights into foreign language teaching.

The paper is organized as follows: the next section provides a brief explanation of the corpus based analysis. Section 3 reviews some studies in the literature involving the major differences between the double object and dative constructions. Section 4 and 5 respectively present the methodology of research and the details of the analysis. Section 6 present the concluding remarks and teaching implications of the paper.

\section{Corpus Based Analysis}

The proliferation of corpus systems and techniques has enabled researchers worldwide to conduct research in their own geographical location with minimal hindrance (Xie, 2013). It has also been noted that over the years, corpus techniques have transformed the landscape of empirical research relating to linguistic studies and language education.

$\mathrm{Xu}$ (2014), explains that corpus-based research distinguishes itself primarily by the fact that it is based on authentic language in real contexts, thus providing a more concrete description of language. Corpora can be used in a wide range of research applications, including grammatical studies of specific structures, language variation, contrastive analysis, and language acquisition, to name but a few $\mathrm{Xu}$ (2014).

This important role of corpus-based research in linguistic and language teaching and learning is largely observed in Xie (2013)'s paper reporting a state-of-art review of recent development on corpus linguistics and corpus-based research in Hong Kong where five major focuses are identified. Out of the 29 listed research projects, 12 studies are conducted to inform language teaching and learning and 11 research studies have a primary focus on linguistics and languages.

The present study is a continuation of some analyses started in Kane (2019), investigating the grammatical errors made by Senegalese English majors. The paper uses a corpus from French-English grammatical translation and examines, learners' ability to use TELL and SAY, two synonymous ditransitive verbs which generally appear in different expressions.

\section{Previous Studies on Ditransitive Constructions}

Much literature has been produced on the characteristics of double object construction (DOC) and dative or prepositional (DAT) construction of ditransitive verbs in English.

Referring to several studies, Siewierska and Hollman (2007) explain the syntactic, semantic and pragmatic characteristics of the two constructions materialized in (1a) John gave a book to Mary and (1b) John gave Mary a book. For these authors, syntactically the two are typically seen to differ with respect to grammatical relations; the recipient (being an indirect object or under some analyses a direct object in (1b) but not in (1a). Semantically, the double object construction is viewed as highlighting the transfer of possession, the prepositional construction the location of the transferred item. And pragmatically, the double object construction is associated with topical recipients and focal themes, the prepositional construction with topical themes and focal recipients.

Gries and Stefanowitsch (2004), conducted a corpus-based study of the British component of the International Corpus of English (ICE-GB). They investigated pairs of semantically similar construction, including the English dative construction. A range of alternating ditransitive verbs were studied, with the ordering based on the ranking of 'distinctiveness' towards the double object structure or the to-dative structure. 'Distinctiveness' means the degree to which the lexemes are attached to a particular construction. Table (1) is adapted to (Xu, 2014).

Table-1. Collexemes distinguishing between the ditransitive and the to-dative

\begin{tabular}{l|l|l|l}
\hline \multicolumn{2}{l|}{ Double object $(\mathbf{N}=\mathbf{1 , 0 3 5})$} & To-dative $(\mathbf{N}=\mathbf{1 , 9 1 9})$ \\
\hline Collexeme & Distinctiveness & Collexeme & Distinctiveness \\
\hline give $(461: 146)$ & $1.84 \mathrm{E}-120$ & bring $(7: 82)$ & $1.47 \mathrm{E}-09$ \\
\hline tell $(128: 2)$ & $8.77 \mathrm{E}-58$ & play $(1: 37)$ & $1.46 \mathrm{E}-06$ \\
\hline show $(49: 15)$ & $8.32 \mathrm{E}-12$ & take $(12: 63)$ & 0.0002 \\
\hline offer $(43: 15)$ & $9.95 \mathrm{E}-10$ & pass $(2: 29)$ & 0.0002 \\
\hline cost $(20: 1)$ & $9.71 \mathrm{E}-09$ & make $(3: 23)$ & 0.0068 \\
\hline
\end{tabular}

Table (1) shows that give distinguishes between the two constructions by most significantly preferring the double object construction to the to-dative, while bring favours the prepositional dative construction. Xu concludes 


\section{Sumerianz, Journal of Education, Linguistics and Literature}

that this research is of great significance in that it gives a satisfactory account of the relationship between verbs and constructions by presenting empirical corpus data.

$\mathrm{Gu}$ (2009), studied the Chinese Learner English Corpus (CLEC), and compared the data with those in the native-speaker BROWN Corpus. Following Goldberg's Construction Grammar, an analysis of the results from the perspectives of verb types, construction senses, and argument roles was made. Findings of this study generally showed that Chinese learners tend to overuse the ditransitive constructions, with a smaller range of verb types, compared to the native speakers. In addition, learners of different proficiency levels exhibit dissimilar features in the use of the ditransitive forms, with the advanced learners having a better mastery of ditransitives.

Considering the item-based learning process to explain the most frequently occurring configurations of TELL + Pronoun $+N P$ in the beginner corpus, $\mathrm{Xu}$ claims that the second language is learned on an exemplar-based models. Through a step-by-step learning process, L2 learners first get familiar with the fundamental usages of the ditransitive structure, and as learning continues, they will gradually master more complicated patterns.

Still following the usage-based model, Year and Gordon (2009), also investigated the effects of providing a skewed learning schedule for the ditransitive construction in which examples are loaded in favour of the give prototype. After analysing the Korean speakers' acquisition of the English ditransitive construction, they suggest that language learners must not only learn the ditransitive syntactic patterns and their abstract meanings but also must build a semantic network of verb cluster and keep track of the particular ways those verbs are instantiated in argument structures for their particular language (Year and Gordon, 2009). According to the latter, the main challenge facing usage-based acquisition theorists in this domain is to provide an account of how language learners come to form an abstract representation for the ditransitive construction on the basis of input alone, enabling them to comprehend and produce the correct forms of ditransitive expressions and, at the same time to productively use this construction with novel verbs

Goldberg (1995) and her colleagues have shown that teaching a novel construction using a high-frequency prototypical verb can be facilitative for initial construction learning. However; Year and Gordon (2009) indicate that such a strategy is limited in L2 learning and might interact with other factors such as the nature of a construction, implicit / explicit learning mode adopted during learning, the number of stimuli taught, exposure duration, the order in which stimuli are presented, and construction complexity, which could each make a difference in the way constructions are best learned in a particular context.

Under the Senegalese educational system, French is the language of instruction. Still, basing on the same system, English is taught to all learners for 7 years before they start their high studies, where they also follow English classes with a time exposure that varies depending on the speciality. It is expected, then, that university students, especially English majors, achieve oral and written proficiency in this language. What has, however, been noted is a great number of them are faced with grammatical difficulties such as ditransitive forms.

For instance, it is common to hear the ditransitive TELL and SAY being mistakenly alternated as in *He didn't tell that he had taken the book (Kane, 2019), where the correct verb is not TELL but SAY. It is also observed that, these errors in the use of ditransitive verbs are very recurrent in French, the first learnt language. In French, the indirect objects 'lui' (him, her) and leur (them) are often mistakenly replaced by their direct equivalents ' $l e$ ', ' $l a$ ' (him, her, it) and les (them) as shown in the following sentence taken from a post on Facebook *Ma femme me réveillait en pleine nuit pour que je la trouve à manger (My wife used to wake me up in the middle of the night to find her something to eat). In this sentence the $3^{\text {rd }}$ person singular indirect object lui is mistakenly replaced by the direct object la.

Since the acquisition of ditransitive constructions is challenging for students both in French and English, it could be hypothesized that ditransitive verbs are, by nature, difficult to learn. However, it is believed that more research including error analysis and contrastive method could help to comprehend and give effective remedial to errors made in this sense.

The current paper uses the Error Analysis approach and aims at informing teachers about the learners' difficulties to use ditransitive verbs; and secondly, to help learners correct these errors by themselves.

\section{Methodology}

The study is conducted with students from the second-year level in the English department of Cheikh Anta DIOP university of Dakar (Senegal). These learners took an annual course on grammar during the academic year 2019-2020. To conduct this research, I used copies of the second semester evaluation. The exam consisted of three exercises including (1) completing a set of sentences with the right quantifiers), (2) filling gaps with the right articles, and finally (3) translating four French sentences into English. The present data is collected from the last exercise, French-English translation.

While grading, the translation of this particular sentence: "Mes baguages ont disparu et ils ne m'ont rien dit" which has several equivalents in English, among others 'My luggage has disappeared and they didn't tell me anything' drew my attention. These English sentences showed many errors ranging from the corresponding verb of DIRE (tell, say), verbs' structures (double object or dative) and the choice between the pronoun 'nothing' and 'anything', to name but a few. Then, I selected 200 copies at random with the focus on identifying the patterns underlying ditransitive expressions in English.

\section{Results and Data Analysis}

After collecting the data, the next task is to make an inventory of the various forms used to translate the French ditransitive verb DIRE. The second task consists to identify the different complementation patterns involving the two 
transitive verbs: TELL and SAY. The third section investigates what influences the acquisition of the better used form.

\subsection{Presentation of the Overall Forms in the Translation of "DIRE"}

Learners of the present study have used three English verbs: TELL, SAY and TALK to translate the French DIRE. Another translation pattern includes monotransitive forms (omission of one object) while non-translated sentences and misunderstood forms are put in one category labelled "Other Forms". Table (2) presents all these mentioned patterns.

Table-2. The overall forms in the translation of "DIRE"

\begin{tabular}{l|l|l}
\hline Pattern & Frequency & Percentage \\
\hline TELL & 125 & $62,5 \%$ \\
\hline SAY & 29 & $14,5 \%$ \\
\hline TALK & 8 & $4 \%$ \\
\hline Monotransitive Forms & 30 & $15,5 \%$ \\
\hline Other Forms & 8 & $3,5 \%$ \\
\hline Total & 200 & $100 \%$ \\
\hline
\end{tabular}

\section{TELL}

Table (2) shows that a great number of the students translate the French verb DIRE using the English equivalent TELL. For instance, out of the 200 English sentences, 125 involve the ditransitive TELL, representing 62, 5\% of the whole data.

$S A Y$

The overwhelming use of TELL suggests that learners largely prefer TELL to SAY which is only used by 29 of them or $14,5 \%$ of all the participants.

\section{TALK}

As presented in table (2) above, 8 learners translate the French verb DIRE, using TALK instead of TELL or SAY. But as indicated in Swan (1996), TALK is a more usual word to refer to conversational exchanges e.g. When she walked into the room everybody stopped talking. According to Swan TALK is also often used for the act of giving an informal lecture (a talk) as in: This is Mr Patrick Allen, who's going to talk to us about flower arrangement. It is indicated here that TALK is monotransitive in the first sentence but ditransitive in the second with two prepositions: to and about. However, even if this verb can be ditransitive, its meaning doesn't correspond to that of TELL and $S A Y$. Therefore, it is excluded from the present study.

\section{Monotransitive forms}

30 instances are also listed from the data where TELL and $S A Y$ are used in their monotransitive forms. It means that while translating, the learners do not exhibit the two objects. They omit either the direct as in (1) and (2) or the indirect object of the verbs as (3) and (4) show.

1. My luggage has disappeared and they didn't say anything.

2. My luggage disappeared and they said nothing.

3. My luggage has disappeared and they didn't tell me

4. My luggage is lost and they haven't told me.

What the analysis also indicates is, the indirect object (OI) tends to be more omitted with 21 instances while only 9 sentences involve an absence of direct object (OD). This finding corroborates previous studies like Carnerero (2007) who argues that although in the prototypical ditransitive construction in English, both objects are present, there is often omission of one of the constituents, usually the indirect object. And, according to her, the absence of the indirect object has been justified on the basis of the irrelevance of its specification or the possibility of recovering it from the context. The absence of the direct object, on the other hand, is not so common and only occurs with a restricted number of verbs (e.g. pay, show or tell) (Carnerero, 2007).

Since this paper focuses on ditransitivity, these monotransitive forms are also excluded from the analysis.

\section{Other Forms}

This category named 'Other Forms' involves 2 distinct patterns. In the process of data analysis, I found that 3 learners omitted to translate this said sentence while 5 others used some erroneous forms that could not be classified in any of the above mentioned categories.

\subsection{Identification of the Different Complementation Patterns of TELL and $S A Y$}

This section extracts the use of TELL and $S A Y$, corresponding to a total of 154 translated sentences out of the initial 200 ones. Before starting the analysis, let's recall that:

With TELL, the direct object (OD) follows the indirect object (OI) as shown in its basic structure TELL someone something. This is known as the Double Object construction (DOC). On the other hand, when $S A Y$ is used, the direct object comes first and is linked to the indirect one with the preposition "to" as in SAY something to someone. This second form is called prepositional or (to) dative construction (DAT). Table (3) below presents the distribution of TELL and SAY in the two constructions 
Sumerianz Journal of Education, Linguistics and Literature

Table-3. Distribution of TELL and $S A Y$ in the double-object and dative constructions

\begin{tabular}{l|l|l}
\hline DOC / DAT & Frequency & Percentage \\
\hline TELL in DOC & 122 & $79,2 \%$ \\
\hline TELL in DAT & 3 & $1,9 \%$ \\
\hline SAY in DOC & 21 & $13,6 \%$ \\
\hline SAY in DAT & 8 & $5,1 \%$ \\
\hline Total & 154 & $100 \%$ \\
\hline
\end{tabular}

Table (3) shows that TELL doesn't only occur in the expected double object construction. Some learners happen to use it in the dative form. The same patterns apply to $S A Y$ which is employed in the two constructions. Details of all these ditransitive forms are given below.

\subsubsection{The Complementation Patterns of TELL}

The first observation is TELL overwhelmingly appears in the double object construction in accordance with English grammar. The data analysis shows 122 translated sentences where TELL occurs in this structure: TELL+ indirect object (somebody) + direct object (something). This suggest that the current learners have knowledge about the use of TELL in a ditransitive construction, as exemplified in (5) and (6).

5. My luggage has disappeared and they told me nothing

6. My luggage disappeared and they didn't tell me anything

These findings correspond well to Xu (2014) who found that similar to British native speakers, Chinese learners also exhibit knowledge about the specific constructions of TELL. Additionally, both advanced and beginning learners significantly prefer to use TELL in DOC as it is the case in the present study.

However, this overwhelming use of TELL in the double object form doesn't imply that all the learners master ditransitive constructions with such verb. For instance, as shown in table (3), 3 of them mistakenly use TELL in the dative form as (7) and (8) indicate.

7. *My luggage are lost and they told nothing to me

8. *My baggage are not here and they have told nothing to me

\subsubsection{The Complementation Patterns of SAY}

Like TELL, SAY is also mainly used in double object construction. The data shows that 21 instances of ditransitive constructions involving $S A Y$ appear in this form against 8 in the to-dative construction. It means that using $S A Y$ as a ditransitive verb is a difficult task for a large number of these learners. As already explained, out of the 29 participants who tried this form, only 8 apply the rule correctly. The remaining 21 students make what is called the dative shift and employ $S A Y$ in a double object construction as indicated in (9) and (10), which does not conform to English grammar.

9. *Someone has stolen my luggage and they said me nothing.

10. *My baggage disappeared and they didn't say me anything.

To explain this dative shift, Stefanowitsch (2008) states that a learner might hypothesize that all verbs that occur in the dative construction can also occur in the double object construction. However, this hypothesis turns out to be overly general as the following judgements show: Dad said something nice to Sue and *Dad said Sue something nice.

This overgeneralization may also hold for some learners of this corpus using $S A Y$ in the double object construction while it is only expected in the dative form. One reason of this process can provide from the fact that even if TELL usually occurs in the double object construction, it also happens to use it in the dative form when the complement is long as example (11) shows.

11. He told his story to his many friends in Paris (www.kakouridis.net).

Then, it can be believed that the fact that TELL is an alternating ditransitive verb accepting both the double object and dative constructions, influences these learners to use $S A Y$ also in the two constructions. Another generalization that may derive from the alternating characteristics of TELL is that when TELL mainly refers to the French verbs "raconter" or "parler de", it is followed by the direct object as it appears in these common expressions: tell a story, tell a lie, tell a joke, tell the truth etc. We have, then, a dative construction with: Tell + something + to + someone instead of the usual double object structure Tell + someone + something.

The different complementation patterns of both TELL and SAY have demonstrated that the order of ditransitive construction with TELL is more respected by these learners. In a total of 125 occurrences, only 3 are erroneous. On the other hand, 8 uses of say are correct out of 29 . This specifically implies that learners of the corpus master the double object construction better than the to-dative form. The question that should be addressed here is what influences the acquisition of this double object construction?

\subsection{Indirect Object Pronouns Facilitate the Acquisition of the Double Object Construction}

According to many researchers, the fact that the indirect object (OI) of TELL often appears as a pronoun, influences on the frequent use of the double object construction.

$\mathrm{Xu}(2014)$ noted that the indirect object is most frequently realized by a pronoun across the three corpora of his study: low-proficiency learners, high-proficiency learners and native speakers. He further states that with the help of pronouns, ' $m e$ ' in particular, beginning learners have developed the knowledge of how to use TELL in double object structure. 


\section{Sumerianz, Journal of Education, Linguistics and Literature}

Gries and Stefanowitsch (2004) also found that in the Spanish learner data, the thematic role recipient (indirect object) was most commonly realized by a pronoun. That is, structures like give + Pronoun + Theme were found to be more frequent than give + Proper Noun + Theme or give + Full Noun + Theme. Drawing on Tomasello (2003) notion of 'constructional islands', Manzanares and Lopez (2008) argued that "language learners master first a specific form of the construction with pronouns which later on gets extended to proper nouns and other types of phrases.

As these authors claim, pronouns facilitate the acquisition of a construction in early language learning. One can deduce, then, that such type of construction is among the basic ones of the language. The recurrent use of pronouns noted in the double object construction can therefore suggest that this form is more basic than the dative one in ditransitive constructions. And, it can even be argued that this basic criterion of the double object construction explains why it is the easier and more correctly used in this study.

\section{Concluding Remarks and Teaching Implications}

This paper has analysed the construction of two synonymous ditransitive verbs TELL and SAY which appear in distinct structures. On the basis of a corpus data collected from 200 second-year students, the study comes with two general observations.

Findings first show that TELL is by far more preferred to SAY. For instance, 62, 5\% of these learners translate the French verb DIRE by TELL against 14, 5\% using SAY. The remaining ones employ TALK (4\%), the monotransitive form $(15,5 \%)$ and finally other patterns, labelled "Other Forms" (3, 5\%).

The analysis also indicates that learners of this corpus better master how to form the ditransitive construction with TELL. There are 122 translated sentences out of the 200 initials where TELL occurs in this structure: TELL+ indirect object + direct object, corresponding to the structure TELL + somebody + something. Nevertheless, 3 instances have been listed where TELL is mistakenly used in the to-dative form.

Results of the study also show that using $S A Y$ as a ditransitive verb is a big challenge for a large number of these learners. That is, out of the weak number of participants (29) who tried the dative form, only 8 apply the correct rule which is: $S A Y+$ direct object + to + indirect object, conforming to $S A Y+$ something + to + someone. All the remaining 21 students mistakenly use $S A Y$ in a double object construction.

The literature claims that the reason why the double object construction is most frequently used than the dative form (with $S A Y$ ) is that indirect object of TELL is usually realized by a pronoun.

According to these researchers, pronouns facilitate a construction acquisition in early language learning. That's why this study deduces that, because of the recurrent use of pronouns noted in the double object construction, this form would be more basic and easier than the dative one. This is why it is more correctly used in this corpus.

Even if this paper is concerned with only two verbs TELL and SAY, it still sheds some light on second language teaching and learning. As the study indicates, learners of this research are not beginners, they are English majors who have learned these ditransitive structures quite early. Nevertheless, they are still in their basic level in the acquisition of these forms. This suggests that effective remedial should be done on teaching ditransitive construction, especially on the dative form. Results of the present study also imply that more efforts are required on teaching constructions in grammar in general. As Boars (2010) states, grammatical constructions are the fundamental building blocks of language.

Several studies reviewed in this paper have suggested that pronouns help in language learning, this item-based learning process could be tested and employed as a method of teaching and learning other grammatical categories.

\section{References}

Carnerero, C. A., 2007. "On "Dimonotransitive"." In Structures in English, Conference on.

Goldberg, A. E. (1995). Constructions: A construction grammar approach to argument structure. University of Chicago Press.

Goldberg, A. E. (2003). Constructions: a new theoretical approach to language. TRENDS in Cognitive Sciences, 7(5): 219-24.

Goldberg, A. E. (2006). Constructions at work. Oxford University Press.

Gries, S. T. H. and Stefanowitsch, A. (2004). Extending collostructional analysis: A Corpus-based perspective on “alternations. International Journal of Corpus Linguistics, 9(1): 97-129.

$\mathrm{Gu}, \mathrm{L}$. (2009). A corpus-based study of ditransitive construction in Chinese college learners English writing. MA thesis. Southwest Jiaotong University.

Haspelmath, M. (2005b). Ditransitive constructions: The verb 'give'; In martin haspelmath, matthew s. Dryer, david gil and bernard comrie (eds.), the world atlas of language structures. Oxford University Press. 426-29.

Kane, H. (2019). An analysis of grammatical errors made by senegalese English majors. Addiyan Journal of Art, Humanities and Social Sciences, 1(10): 64-76.

Malchukov, A. L. (2007). Reciprocal and sociative constructions in Even. Typology of reciprocal constructions Nedjalkov, V.P. (ed.): Amsterdam: Benjamins. 1643-75.

Manzanares, J. V. and Lopez, A. M. R. (2008). What can language learners tell us about constructions. Cognitive approaches to pedagogical grammar. Mouton de Gruyter S. D. Knop and T. D. Rycker (eds): Berlin and New York. 197-230.

Richard, J. C. and Schmidt, R. (2002). Longman dictionary of language teaching and applied linguistics. 3rd ednPearson Education Limited. 
Siewierska, A. and Hollman, W. B. (2007). A construction grammar account of possessive constructions in Lancashire dialect: some advantages and challenges. English Language and Linguistics, 11(2): 407-24.

Stefanowitsch, A. (2008). Negative entrenchment: A usage-based approach to negative evidence. Cognitive Linguistics, 19(3): 513-31.

Tomasello, M. (2003). Constructing a language. Harvard University Press.

Xie, Q. (2013). Corpus linguistics and corpus-based research in Hong Kong: A state-of-art review. English Language and Literature Studies, 3(3): 48-55.

$\mathrm{Xu}, \mathrm{Q}$. (2014). A Corpus-based study of the alternating ditransitive verb TELL in native and Chinese learner English corpora. ICAME Journal, 37(2): 185-205.

Year, J. and Gordon, P. (2009). Korean speakers' acquisition of the english ditransitive construction: The role of verb prototype, input distribution, and frequency. The Modern Journal, 93(3): 399-417. 